\title{
Entrevista com Luiz Ruffato
}

Joelma Santana Siqueira (Universidade Federal de Viçosa) Vivaldo Andrade dos Santos (Georgetown University)

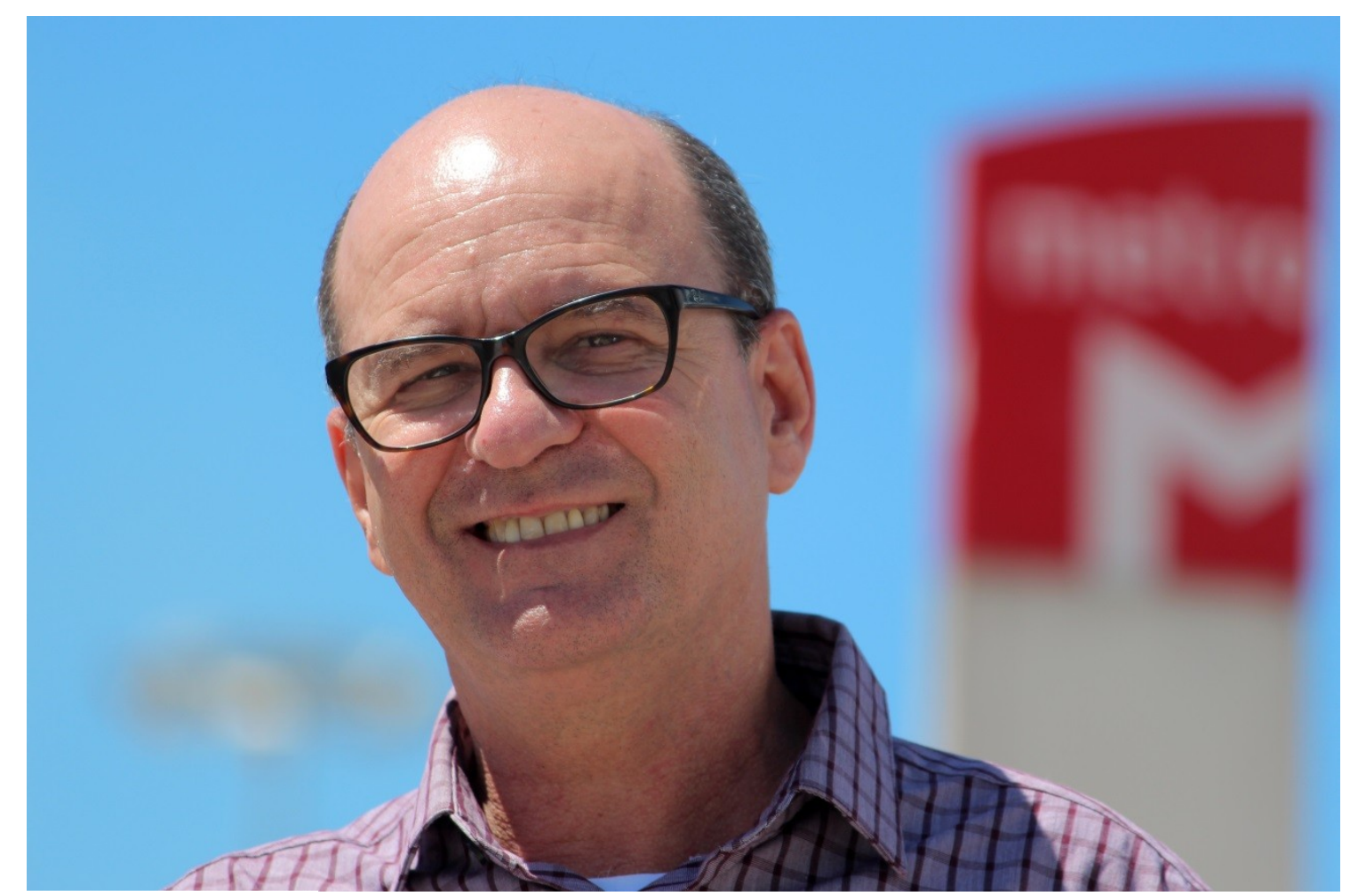

Fonte: Arquivo do autor.

Luiz Ruffato - Lançou Eles eram muitos cavalos (2001), Estive em Lisboa e lembrei de você (2009), Flores artificiais (2014), De mim já nem se lembra (2015), Inferno provisório (2016), O verão tardio (2019), todos romances; As máscaras singulares (poemas, 2002); Minha primeira vez (2014), crônicas; A história verdadeira do Sapo Luiz (2014), infantil; e A cidade dorme (2018, contos). Seus livros ganharam os prêmios Machado de Assis, APCA, Jabuti e Casa de las Américas e estão publicados na Argentina, Colômbia, Cuba, México, Estados Unidos, Portugal, França, Itália, Alemanha, Finlândia, Macedônia, Moçambique e, em breve, Israel e Índia. Em 2012 foi escritor-residente na universidade de Berkeley (Estados Unidos) e em 2016 recebeu o Prêmio Internacional Hermann Hesse, na Alemanha.

Gláuks: Revista de Letras e Artes - jul/dez 2020 - v. 20, n. 2 
1. Prezado Luiz Ruffato, somos muito gratos a você por nos conceder essa entrevista para o presente dossiê da Gláuks dedicado ao tema "A literatura brasileira no exterior". Para iniciarmos, pedimos que nos fale sobre como é escrever e publicar literatura no Brasil.

Para responder objetivamente a essa pergunta, vamos a alguns números. A taxa de analfabetismo no Brasil é de cerca de 7\% do total da população, mas se consideramos dados referentes ao analfabetismo funcional, chegaremos ao espantoso fato de que apenas oito em cada cem brasileiros são plenamente capazes de entender e se expressar por letras e números... O número de livrarias vem caindo vertiginosamente - hoje chegam a algo em torno de 2,5 mil lojas, quando deveriam ser 20 mil, pela régua da Unesco (uma livraria para cada 100 mil habitantes). O mercado editorial encolheu $20 \%$ ao longo da última década. O índice de leitura per capita no Brasil é de 2,9 livros por ano, um dos mais baixos do mundo. E, infelizmente, diante da tragédia da pandemia do coronavírus, esse quadro, já por si desalentador, vai piorar substancialmente. Num país onde a educação não é direito, mas privilégio, onde a cultura é artigo de luxo, e onde a elite demonstra um profundo desprezo pelos marcos de civilidade, ser escritor é um ato de subversão.

2. Você considera que há diferenças que mereçam ser destacadas entre a recepção que sua obra tem no Brasil e a que tem no exterior?

Sem dúvida. No Brasil, não temos recepção crítica em jornais e revistas - porque, além de tudo, não temos jornais e revistas... A crítica hoje encontra-se encapsulada em alguns nichos do mundo acadêmico que, apesar de vir cumprindo relativamente bem o seu papel, se defronta com dois obstáculos quase intransponíveis: o hermetismo de linguagem e o abismo que a separa da sociedade. Além do que, o Brasil, por ser um país tacanhamente provinciano, continua funcionando na base do compadrio e das modas ditadas pelos Estados Unidos. Não basta você escrever um livro - aqui, você tem que se tornar parte do espetáculo, o que faz com que pessoas medíocres, mas bons manipuladores de mídias sociais, se tornem fenômenos

Gláuks: Revista de Letras e Artes - jul/dez 2020 - v. 20, n. 2 
literários... No exterior, há resenhas sérias em jornais e revistas e, para minha surpresa, nos rádios e televisões. Há um sistema literário organizado e eficaz, que valoriza cada engrenagem - sendo o autor a principal delas. As editoras publicam os livros, a mídia os avalia, as livrarias os vendem - e todos nessa cadeia ganham seu quinhão.

\section{Qual a importância da tradução, sobretudo, para o escritor que escreve em português?}

Há algumas questões relevantes que tornam a tradução importante para o escritor. A primeira delas é que quem escreve quer ser lido. E quanto mais leitores - seja em sua própria língua, seja em línguas estrangeiras, melhor. A sua mensagem alcançará maior repercussão. A segunda é financeira. A circulação de livros no exterior é garantia de pagamentos de direitos autorais (em geral, os chamados avanços compreendem um valor aproximado referente à venda de toda uma primeira edição) e também a possibilidade de surgirem convites para feiras e festivais literários, que pagam cachês e também ajudam na construção de uma carreira profissional. E há ainda uma terceira questão: por sermos um país provinciano, quando há interesse, no exterior, por algum autor, imediatamente ele passa a ser mais valorizado internamente...

\section{Quais são os desafios para ser publicado no exterior ou ser traduzido para outra língua?}

Como o mercado editorial brasileiro é ainda bastante amador, padecemos com a falta de dois elementos fundamentais para a divulgação da literatura no exterior e, por consequência, para despertar interesse nas editoras para sua tradução e publicação. Praticamente não contamos com agentes literários - os que existem no Brasil não completam os dedos de uma mão. E essa figura é essencial para que os nossos títulos cheguem às mãos das editoras estrangeiras - é o agente literário que media esse negócio... O segundo elemento

Gláuks: Revista de Letras e Artes - jul/dez 2020 - v. 20, n. 2 
que nos falta é uma política pública clara e perene em relação ao livro. Todos os países sérios do mundo têm uma instituição dedicada ao fomento do livro no exterior, seja patrocinando traduções, seja patrocinando a circulação de autores por feiras e festivais, seja patrocinando cadeiras em universidades importantes. Infelizmente, não temos nada disso. Houve, na primeira década do século XXI, um incipiente, mas importante, começo de atuação da Biblioteca Nacional - que ampliou os valores das bolsas de tradução e atuou com alguma competência para divulgar a literatura brasileira, mas, como tudo no Brasil, não passou de chuvas de verão...

\section{5. "Traduttore, traditore". Como é ler sua obra traduzida para outro idioma? Destacaria algum exemplo?}

No meu caso, há dois tipos de tradutores: aqueles que fazem seu trabalho sem nunca me procurarem - a minoria - e aqueles que me consultam para resolver dúvidas. O tradutor, na minha opinião, é quase tão importante quanto o autor. Inclusive, advogo sempre que em meus livros constem na capa meu nome e o nome do tradutor, porque ele é o verdadeiro agente da recepção da literatura em outra língua. Eu aprendi e aprendo muito sobre meus próprios livros com os questionamentos dos tradutores - pois, antes de tudo, o tradutor é um leitor arguto. O bom tradutor não é aquele que transfere palavras de um idioma para o outro, mas sim aquele que traduz culturas... Meus livros estão publicados em treze países e sete idiomas (além de Portugal) - e sou muito grato a todos os tradutores por levarem minhas histórias para viajarem pelo mundo.

\section{Existe uma "literatura nacional”, presa a um país, a uma região, a uma língua?}

Existe literatura produzida numa língua - ela é o substrato essencial para sua existência. Mas isso não significa que haja uma literatura presa a um país, a uma região... Se é boa literatura ela transcende essas fronteiras artificiais e ignora esses códigos ultrapassados.

Gláuks: Revista de Letras e Artes - jul/dez 2020 - v. 20, n. 2 


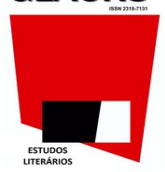

Por isso a importância fundamental da figura do tradutor. Para mim, literatura de qualidade é aquela que alcança essa transcendência: um texto escrito em uma língua específica, contando uma história passada num lugar específico e num tempo específico e que pode ser compreendida em outra língua, em outra região, em outro tempo...

7. Seu fazer literário busca responder a alguma urgência presente na realidade social brasileira que você gostaria de destacar?

Meus livros, quase todos, tentam representar a classe média baixa brasileira. Um recorte social quase sempre ausente da literatura (e das Artes em geral), que se ocupa ou com a classe média média e alta ou com as populações marginais. Me interessa discutir como a História (a superestrutura) impacta esse recorte social, que representa a imensa maioria da população brasileira.

Gláuks: Revista de Letras e Artes - jul/dez 2020 - v. 20, n. 2 